\title{
Paradigmatic and Syntagmatic Effects in Estonian Spontaneous Speech
}

\author{
Kaidi Lõo \\ University of Tartu, Estonia
}

\section{Fabian Tomaschek}

University of Tübingen, Germany

\section{Pärtel Lippus}

University of Tartu, Estonia

\section{Benjamin V. Tucker}

University of Alberta, Canada; University of Tübingen, Germany

\begin{abstract}
Recent evidence indicates that a word's paradigmatic neighbors affect production. However, these findings have mostly been obtained in careful laboratory settings using words in isolation, and thus ignoring potential effects that may arise from the syntagmatic context, which is typically present in spontaneous speech. The current corpus analysis investigates paradigmatic and syntagmatic effects in Estonian spontaneous speech. Following work on English, we focus on the duration of inflected and uninflected word-final/-s/ in content words, while simultaneously investigating whole words. Our analyses reveal three points. First, we find an effect of realized inflectional paradigm size, such that smaller paradigms actively used by the speakers lead to longer durations. Second, higher conditional probability is associated with shorter word forms and shorter segments. Finally, we do not directly replicate previous work on effects of inflectional status as in English word-final /-s/. Instead, we find that inflectional status interacts with conditional probability. We discuss the results in light of models of speech production and how they account for morphologically complex words and their paradigmatic neighbors.
\end{abstract}

\section{Keywords}

Morphological complexity, inflection, paradigm size, conditional probability, acoustic durations 


\section{Introduction}

Experimental studies investigating paradigmatic effects during speech production demonstrate that smaller morphological paradigms and higher paradigmatic probability are correlated to longer acoustic durations (e.g., Lõo, Järvikivi, Tomaschek, et al., 2018, and references therein). However, few researchers have used actual spontaneous speech production data or considered the effect of context on these productions. Moreover, many of these studies have investigated relatively morphologically simple languages (see Plag, 2014; Strycharczuk, 2019, for recent overviews on morphological effects in production). English has only two-noun cases (Quirk et al., 1985) and is the most frequently studied language in terms of paradigmatic effects. Other languages studied include German with four cases (Drosdowski \& Eisenberg, 1998), and Serbian with five cases (Hamm, 1981).

The question therefore arises whether and how paradigms play a role for the representation and production of languages with more complex morphological systems, such as Estonian (with 14 cases). In contrast to paradigmatic effects, syntagmatic effects in speech production have been studied in more depth. It has been demonstrated that the phonetic characteristics of words and segments vary with syntagmatic context. Contextually more predictable segments and words have shorter acoustic durations than less predictable segments and words (e.g., Aylett \& Turk, 2004; A. Bell et al., 2009). It is less clear whether systematic changes in speech acoustics in relation to paradigmatic structure remain present, when syntagmatic effects are taken into account. So far, only Cohen (2015) has demonstrated that paradigmatic effects emerge when syntagmatic effects are accounted for, when these effects are studied in laboratory speech.

This study addresses this question by investigating how paradigmatic and syntagmatic structures correlate with phonetic characteristics at the word and segment level in Estonian spontaneous speech. In this way, we obtain a broader picture of the interaction between a word's morphological structure, its paradigmatic family, and the context it is located in. To anticipate our results, we find both contextual and paradigmatic effects on word and segment durations in Estonian. Interestingly, contextual effects also interact with the internal morphological structure of the word.

In the next sections, we first provide some phonological and morphological background on Estonian. Subsequently, we discuss previous literature on morpho-phonetic interactions as well as whether and how models of speech production have been able to account for the findings. Then, we describe two phonetic analyses of data obtained from a corpus of Estonian spontaneous speech. We conclude this paper with a discussion of how our findings relate to models of speech production.

\section{I.I Estonian language}

Estonian is a Finno-Ugric language with a complex phonological and morphological system. At the phonological level, Estonian has nine vowels and 17 consonants (Asu \& Teras, 2009; Eek \& Meister, 1999) (or 18 consonants according to Viitso, 2003). Estonian syllables contain one vocalic nucleus and are optionally preceded or followed by one to four consonants (Viitso, 2003). In Estonian, word stress is usually on the first syllable. Yet, the duration of stressed and unstressed syllables can vary systematically as syllables participate in a three-way quantity contrast, which Estonian is probably best known for in the phonological literature. This three-way quantity contrast is an important phonological feature of Estonian that has strong implications for potential duration changes. From a phonological perspective, the quantity contrast is not a segmental contrast but a prosodic one (Eek \& Meister, 1999). It is manifested in the ratio between duration of 
Table I. Inflectional Paradigm of hammas "tooth" with 45 Members.

\begin{tabular}{lll}
\hline Case & Singular & Plural \\
\hline Nominative & hammas & hambad \\
Genitive & hamba & hammaste \\
Partitive & hammast & hambaid \\
Illative & hambasse, hambu & hammastesse, hambaisse, hambusse \\
Inessive & hambas & hammastes, hambais, hambus \\
Elative & hambast & hammastest, hambaist, hambust \\
Allative & hambale & hammastele, hambaile, hambule \\
Adessive & hambal & hammastel, hambail, hambul \\
Ablative & hambalt & hammastelt, hambailt, hambult \\
Translative & hambaks & hammasteks, hambaiks \\
Terminative & hambani & hammasteni, hambuni \\
Essive & hambana & hammastena, hambaina \\
Abessive & hambata & hammasteta, hambuta \\
Comitative & hambaga & hammastega \\
\hline
\end{tabular}

stressed and unstressed syllables and is co-signaled by pitch movement. In the short quantity (Q1), the stressed syllable is short and open, and the following unstressed vowel is lengthened (e.g., kala /ka.la/, "fish, nominative singular"). In the long quantity (Q2), the stressed syllable is long (either open, e.g., kaalu /ka.lu/ "weight, genitive singular," or closed, kalla /kal.la/ "calla, nominative singular"); in overlong quantity (Q3) the stressed syllable is extra long and the unstressed syllable extra short (e.g., kaalu /ka::.lŭ/ "weight, partitive singular," or kalla /kal:.lă/ “pour, imperative") (Lehiste, 1960; Lippus et al., 2013).

Regarding morphology, the Estonian system has both agglutinative and fusional traits. In agglutinative inflection patterns, stems and affixes are clearly identifiable. For example, in the inessive plural majades "in houses," maja is the stem, -de marks plurality and $-s$ marks the locative case inessive. In fusional patterns, the boundaries between the stem and affixes are less clear. For example, in the partitive plural kalu "fishes" the whole word can be regarded as a stem alternate, or one may distinguish the stem $\mathrm{kal}$ and an affix $-u$ which stands for both the partitive and the plural.

Besides these agglutinative and fusional traits, a special trait of Estonian is its very large inflectional system. Each noun and adjective comes with 14 cases in singular and plural. Three of them are grammatical cases, namely, nominative, genitive and partitive. These are subject and object cases. The other 11 cases are adverbial cases that fulfill the same role as prefixes or suffixes in many other languages: illative, inessive, elative, allative, adessive, ablative, translative, terminative, essive, abessive, and comitative (see Viitso, 2003, more information). The system is further complicated by the fact that many plural forms also have parallel forms, that is, multiple forms for one and the same plural case. Thus, according to Estonian prescriptive grammars (M. Erelt et al., 1995; T. Erelt et al., 2018; Viks, 1992), the number of potential word forms in a nominal paradigm can be over 40. This is illustrated in Table 1 for the noun hammas "tooth."

For verbs, this number is equally as high since verbs in Estonian come with the following inflectional categories: person (first, second, and third, singular and plural), voice (personal and impersonal), tense (present, imperfect, perfect, and past perfect), mood (indicative, conditional, imperative, and quotative) (Viitso, 2003).

Due to the complex morphological patterns, words in Estonian are often very long. Words consist of at least one syllable, but they can consist of up to 12 syllables. However, non-compound 
words are rarely longer than four syllables and usually only up to three syllables in spoken language (Asu et al., 2016, p.155).

With these structural specifications in mind, the question arises whether Estonian's morphological patterns and structures co-determine phonetic characteristics in speech in the same way as has been shown for morphologically simpler languages, such as English (e.g., M. J. Bell et al., 2021; Plag et al., 2017), once contextual predictability is taken into account. In the next sections, we discuss the findings on the relationship between morphological structures and phonetic characteristics.

Two types of morphological information have been found to affect phonetic realizations of complex words: word-internal morphological structures that concern suffixes Plag et al., 2017; Seyfarth et al., 2018) and word-external morphological structure (M. J. Bell et al., 2021; Cohen, 2014, 2015; Kuperman et al., 2007; Lõo, Järvikivi, Tomaschek, et al., 2018) that concern morphological paradigms. We first discuss effects of internal structures as demonstrated in the previous literature.

\section{I.2 Word-internal morphological structures}

Internal structures concern word processes, such as derivation, compounding, or as in the following discussed case, inflectional functions. Several studies have reported systematic duration differences between morphemic and non-morphemic word-final /-s/ as well as differences between different inflectional functions of morphemic/-s/ (Plag et al., 2017; Seyfarth et al., 2018; Tomaschek et al., 2019; Zimmermann, 2016).

For example, Plag et al. (2017) analyzed the duration of word-final/-s/ and /-z/ in a set of 644 manually annotated American English words from the Buckeye Corpus (Pitt et al., 2007). They investigated how the duration of /-s/ and /-z/ varied in relation to its morphological status: nonmorphemic and six types of morphemic word-final/-s/ and /-z/ (plural, genitive, genitive-plural, third-person singular, and cliticized forms). Plag et al. found that non-morphemic /-s/ and /-z/ were produced with longer durations than morphemic /-s/ and /-z/. Regarding morphemic fricatives, inflectional/-s/ and /-z/ were systematically longer than clitics/-s/ and/-z/. There were no duration differences within different types of inflectional and clitics /-s/ and /-z/.

Seyfarth et al. (2018) compared the duration of morphemic and non-morphemic /-s/ and /-z/ in English homophones, such as laps and lapse. In contrast to Plag et al., they found that morphemic /-s/ and /-z/ were longer than non-morphemic word-final fricatives. One potential reason for these opposite findings is that Seyfarth et al. used a set of made-up dialogues created to fit the context of homophone pairs and not natural spontaneous conversational speech.

Plag et al.'s findings were reproduced for a data set containing all 28,928 words which end in /-s/ and /-z/ from the Buckeye Corpus (Tomaschek et al., 2019), as well as for spontaneous speech in New Zealand English (Zimmermann, 2016). Plag et al., (2020) extended the finding from segment durations to word durations and reported that English plural nouns (e.g., boys) were shorter than genitive-plural nouns (e.g., boys, ' but see Schlechtweg \& Corbett, 2021 for no difference in duration for pluralia tantum).

Finally, it has been reported that/-s/ segments also vary in other morphological environments. For example, Smith et al. (2012) showed that transparent affixes (e.g., mis in misbehave) were pronounced with longer duration than pseudo-affixes (e.g., mis in mistake) (see also Baker et al., 2007). In addition to morphemic and non-morphemic fricatives in English, there is literature that shows that prosodic structure influences the phonetic characteristics of sounds. For example, it has been reported that articulatory processes differ depending on the strength and level of prosodic boundaries, including morphological boundaries. Although effects of prosody are far from 
universal, prosodic boundaries have been reported to lengthen acoustic duration or articulatory gestures (Cho, 2004; Keating, 2006; Keating et al., 2003; Krakow, 1999).

These prosodic domain effects include word-internal boundaries, such as morphological boundaries. For example, Cho (2001) observed that the overlap and variability in gestural coordination during the articulation of consonant clusters was larger when the consonants were located at morpheme boundaries than when they were located within a morpheme. Lee et al. (2019) found that consonant vowel (CV) gestures are longer and articulatorily more stable when the CV is located within a morpheme and not across a morpheme boundary. These effects are not categorical but gradient, as demonstrated by Lee-Kim et al. (2013) for the "darkness" of English /-1/. Song et al. (2013) compared words like box and rocks and found that the articulatory gesture is different (higher relative tongue height) for morphologically complex words (e.g., rocks) as compared to the monomorphemic words (e.g., box). Accordingly, Plag et al. (2017) discussed the differences between morphemic and non-morphemic /-s/ in English as a potential effect of prosodic boundaries.

In sum, there is evidence that phonetic characteristics systematically vary with word-internal morphological structures. There is also evidence that phonetic characteristics vary with wordexternal paradigmatic morphological structures. We will discuss these findings in the following section.

\section{I.3 Word-external morphological structures}

Word-external morphological structures concern relations to other words within a morphological family, such as the derivational or inflectional paradigms. There are various measures with which paradigmatic relations can be assessed. For example, Hay (2003) used the relative frequency of inflected forms to the uninflected form (e.g., swiftly, swifter, swiftest vs. swift). She found that the consonant at the boundary between the stem and the affix was more likely to get deleted when the inflected forms were more frequent than the uninflected form (but see Schuppler et al. (2012) for an opposite effect]. Hay, (2003) interpreted this finding to indicate that inflected verbs are composed from smaller units during the cognitive preparation stage of speech production. More precisely, these effects have been explained in line with dual route models (see, e.g., Schreuder \& Baayen, 1995), suggesting that inflected forms will be produced as a whole when the frequency of a form is higher than that of the stem, and as morphemic units when not.

However, this effect can be interpreted to simply indicate that distributional differences among phonologically and semantically related words co-determine the phonetic characteristics of these words. This assumption is supported by studies that assess paradigmatic structures by means of a word form's frequency relative to the cumulative frequency of the entire paradigm, a measure called paradigmatic probability. Cohen (2015) considers the frequency of the inflected form above the frequency of the uninflected form to be equivalent to paradigmatic probability.

Kuperman et al. (2007) investigated the effect of paradigmatic probability on the duration of interfixes in Dutch compounds using an entropy measure, which is estimated from the distribution of relative frequencies within the paradigm of compound words sharing the same first component. Surprisingly, and in contrast to established effects of contextual predictability in syntagmatic contexts (Aylett \& Turk, 2004) as well as in contrast to the probability measure used by Hay (2003), Kuperman et al. (2007) found that the duration of the interfix was longer when the interfix was more probable within the paradigm of compound words. In other words, Kuperman et al. (2007) demonstrated enhancement while one would have expected reduction based on previous findings. They formalized these effects in their "Paradigmatic Enhancement Hypothesis," which states that phonetic contrasts are enhanced when a word's probability is higher within the context of its morphological family. 
Analogous effects were also found in other domains. For example, using a two-noun compound elicitation task in English, M. J. Bell et al. (2021) investigated consonants located at the internal boundary between the two nouns. They reported that boundary consonants were longer, when the family size of the second noun in the compound was smaller. They interpreted smaller family size as equivalent to larger paradigmatic probability of the word in question, as there are fewer possible forms to select from during production. Seen from this perspective, M. J. Bell et al.'s (2021) results mirror those by Kuperman et al. (2007).

While Kuperman et al. investigated paradigmatic relations of compounds, Cohen (2014) changed the perspective to inflectional relations among verbs. Cohen (2014) found that the final /-s/ in the third-person singular English verbs (e.g., looks) was longer when the singular form was more frequent compared to the plural form (e.g., look). In one of the few studies investigating relatively morphologically complex languages, Cohen (2015) looked at vowel suffixes in Russian and demonstrated an enhancement effect in the spectral domain, with higher paradigmatic probability resulting in more extreme formant characteristics in the vowel space. To explain these findings, she appealed to exemplar theory (Goldinger, 1998; Pierrehumbert, 2001) that assumes that each word is represented by a cloud of tokens of that word, which is each phonetically detailed. According to Cohen (2015), multiple paradigm members may be activated in this cloud during production, but the co-activation is mediated by linguistic context and that more plausible words are activated more strongly. However, as mentioned above, Cohen investigated the production of two alternative forms which are both plausible in the context. Accordingly, it is unclear how this approach would explain paradigmatic effects that pertain to all forms used in a paradigm (see M. J. Bell et al., 2021; Kuperman et al., 2007; Lõo, Järvikivi, Tomaschek, et al., 2018) not only to those which are possible within a context.

Tucker et al. (2019) reported paradigmatic effects for the modulation of the duration of stem vowels in irregular English verbs. The irregular past tense stem vowel was longer for words that had more paradigmatic support, that is, more other forms that shared the same kind of vowel (e.g., sang and rang). A similar result was reported for articulatory patterns of stem vowels in English (Tomaschek et al., 2021). Vowels in words with higher paradigmatic probability were produced with larger tongue movements than in words with lower paradigmatic probability (see also Tomaschek \& Ramscar, 2022 for German word-final schwa and Schmitz et al., 2021 for English non-words). These studies explained their results within the discriminative learning framework (Baayen et al., 2019, 2011; Ramscar, 2021; Ramscar et al., 2010), suggesting that these effects emerge from the certainty about the function encoded by a segment: segments are enhanced under higher functional certainty, but reduced under lower functional certainty.

Crucially, all of these effects have been shown for languages with relatively simple morphological complexity, for which it is probable that most or even all members of a paradigm are actually attested in the language's usage. The measures applied in the aforementioned studies focused on the relationship between word forms within a morphological paradigm. Yet M. J. Bell et al. (2021) have also demonstrated that it is not only the relationship within the morphological family, but also the size of the morphological family that matters during speech production. This effect has been shown in compounds and derived words, as they are the only domain in English that actually allows investigation of family size effects. Estonian, by contrast, provides the possibility to do so in inflectional paradigms.

To operationalize inflectional paradigm size in Estonian, Lõo, Järvikivi and Baayen (2018; Lõo, Järvikivi, Tomaschek, et al., 2018) obtained the number of attested forms within an inflectional paradigm from a 15-million Balanced Corpus of Estonian (Kaalep \& Muischnek, 2005). This realized inflectional paradigm size measure reflects actual language use and is motivated by earlier work on Finnish (Karlsson, 1986), another language with a high degree of morphological 
complexity. Karlsson (1986) observed that although each noun in Finnish should have theoretically many case forms, the number of different forms actually present in a corpus is not that large. He suggested that whether or not a noun's forms are used depends on the semantics of the word. For example, he noted that the noun vesi "water" occurs mostly in a series of locative cases, such as the singular inessive vedessä "in the water" or the singular adessive vedellä "on/with the water." Other cases are less frequently or not at all used. The reason for this reduced number of forms of "water" is that in the context of water, something is often in or on the water.

In other words, what seems to count in Finnish, and as we posit in Estonian, is the number of the actually realized word forms in a corpus. For example, in a large Estonian nominal paradigm like that for jalg "foot," words appear in most inflected forms of a paradigm, such as jalad "feet, nominative plural," jalgadel'on the feet, adessive plural,' jalus "in your way, inessive plural," jalas "in the foot, inessive singular," jalaga "with the foot, comitative singular," and so on. At the same time, small-paradigm words like lammas "sheep" are often restricted in language use to a few of the possible inflected forms, such as lammas "sheep, nominative singular," lambad "sheep, nominative plural," lammastele "to the sheep, allative plural," and lambaid "sheep, partitive plural." This is different for the theoretical number of inflectional paradigm members predicted by grammar, which would be very similar for both nouns.

Lõo, Järvikivi, Tomaschek, et al. (2018) investigated effects of the realized inflectional paradigm size on production latencies and acoustic durations in a word naming experiment. They found that inflected nouns from larger paradigms were articulated with shorter latencies and acoustic durations than nouns from smaller paradigms (see also Lõo, Järvikivi, \& Baayen, 2018, for similar findings in comprehension). This measure is in line with M. J. Bell et al.'s (2021) work showing increasing morphological family size decreased the segment durations at the constituent boundary. Importantly, Lõo, Järvikivi, Tomaschek, et al. (2018) showed that realized inflectional paradigm size is a better predictor of production for Estonian than more complex paradigmatic measures, such as inflectional entropy (Moscoso del Prado Martín et al., 2004). However, Lõo, Järvikivi, Tomaschek, et al. (2018) used single isolated inflected words, without syntagmatic context, to study paradigm size, which is why this study specifically examines whether syntagmatic context modulates the effect of paradigm size.

In sum, different researchers have used different measures to evaluate the role of paradigmatic relations in the mental lexicon. However, compared to the opposite effects of internal structure in the past literature, it seems that the majority of previous research suggests that higher paradigmatic probability (smaller inflectional and morphological families as well as less equal distribution with the paradigm) results in phonetic enhancements of words and segments. Whereas internal structure as well as paradigmatic structure has been shown to correlate with the phonetic realizations of complex words, what is less well known is whether they still emerge when syntagmatic effects, such as contextual predictability are controlled. Even though contextual and syntagmatic effects are well established, we will briefly present those findings in the next section that are most relevant to the present study.

\section{I.4 Syntagmatic effects}

The effect of conditional probability within the syntagmatic context is one of the most frequently replicated effects when it comes to relations between phonetic characteristics and lexical structures. In numerous studies, it has been shown that more syntagmatically more predictable words and segments are shorter and vowels are more centralized than less predictable words (Aylett \& Turk, 2004; A. Bell et al., 2003, 2009; Bybee, 2001; Gregory et al., 1999; Jurafsky et al., 2002). Such reduction effects have also been observed in morphemes, even in morphologically complex 
languages. Independently of whether the language under investigation was of low morphological complexity, such as English (Cohen, 2014; Rose, 2017), of medium complexity, such as Spanish (Torreira \& Ernestus, 2012) or of high morphological complexity, such as Kaqchikel (Tang \& Bennett, 2018), the effect is consistent: contextually more probable morphological suffixes are more reduced than those that are less probable.

\section{I.5 Models of speech production}

Effects of predictability in syntagmatic context have been explained by means of the smooth signal redundancy hypothesis (Aylett \& Turk, 2004, 2006) according to which acoustic reductions associated with higher syntagmatic probability are mediated by prosody. Accordingly, syntagmatic effects are explainable in light of extant models of speech production. However, how exactly word-internal and word-external structure effects should be incorporated into models of speech production is still unclear. Specifically, the findings summarized above challenge traditional decompositional models of speech production.

For example, in one of the most influential models of speech production, the Theory of Lexical Access (Levelt et al., 1999) and its computational implementation Weaver ++ (Roelofs, 1997), word-internal structure is not reflected at the articulation level. Since each level of processing is performed in abstract form, the theory predicts that information from higher levels is not available to lower levels. This means that the conceptualization stage only carries information about semantics, the lemma stage about the form and finally, the articulation stage only carries information about separate phonemes. Once the representation is translated from higher to lower levels, the higher level information is lost. Thus, this model could account for an effect of morphological functions at the lemma level, for example, reflected by differences in access speed, but not at the articulation level. Moreover, as this theory does not have a mechanism to account for relations between words, it also does not predict any paradigmatic effects at the articulation level.

While this traditional perspective ignores word-internal structure, that is, relations on the basis of phones and segments, more recent models of the linguistic lexicon, such as the discriminative learning framework or exemplar theory can account for them. For example, recent work within the discriminative learning framework (Schmitz et al., 2021; Tomaschek et al., 2019; Tomaschek \& Ramscar, 2022) has predicted duration differences in homophonous segments discriminating different morphological functions by modeling their functional load based on sublexical and collocational properties. Similarly, in exemplar theory (Goldinger, 1998; Pierrehumbert, 2001), words with their richness of phonetic detail are stored in the lexicon, thus also specific differences according to the morphological function of the word can emerge. In addition, regarding word-external structures, both exemplar theory and discriminative learning models assume complex information, such as information about connections between complex words can be stored in the lexicon. For example, as described above, Cohen (2015) has addressed paradigmatic effects in the framework of exemplar theory and Tucker et al., 2019 and Tucker et al. (2019) and Tomaschek and Ramscar (2022); Tomaschek et al. (2021) in the framework of discriminative learning.

Following these assumptions from exemplar and discriminative learning frameworks, the present study assumes a lexicon which can have complex word-internal relations as well as relations between complex words. We conceptualize that the lexicon is an interconnected network of phonological and semantic relations. Different measures have been proposed to be a component of the connection strength (e.g., phonological neighborhood density, semantic neighborhood density, orthography-semantics consistency) reflecting statistical regularities between words within the network. This study tests whether an additional measure, the realized inflectional paradigm size, could be one of the components of such connection strength. 


\section{I.6 The current study}

In this study, we investigate how word-internal and word-external morphological structure correlates with phonetic characteristics of whole words and affixes, while also considering syntagmatic effects in Estonian, a morphologically complex language. We focus on word-final/-s/ which, in Estonian, can be morphemic and non-morphemic.

First, based on other spontaneous speech studies investigating /-s/ in English, (Plag et al., 2017; Tomaschek et al., 2019; Zimmermann, 2016), we expect morphemic word-final/-s/ to be shorter than non-morphemic word-final/-s/. Similarly, according to previous findings in English (Plag et al., 2020), we expect that word durations for morphemic word-final/-s/ words will be shorter than word durations for non-morphemic word-final/-s/ words. Second, following previous experimental work on inflectional paradigm size in a single word context (Lõo, Järvikivi, \& Baayen, 2018; Lõo, Järvikivi, Tomaschek, et al., 2018), we predict that larger inflectional paradigm size will be associated with shorter acoustic durations in spontaneous speech. Third, we expect that conditional probability correlates with segment and word durations in such a way that more probable segments and words are produced with shorter duration as shown by various other studies (Aylett \& Turk, 2004; A. Bell et al., 2003, 2009; Bybee, 2001; Gregory et al., 1999; Jurafsky et al., 2002).

Furthermore, we investigate whether the paradigm size effect is observable when contextual predictability is taken into account. It is possible that if context provides sufficient information about inflection, no effect of paradigm size emerges. Thus, if the effect of paradigm size depends on the context, then we expect an interaction between paradigm size and conditional probability such that no effect of paradigm size is observable for highly probable words. By contrast if the effect of paradigm size is independent of context, (a) it should emerge in spite of controlling for conditional probability and (b) no interaction should be observed. Similarly, we investigate whether internal structure interacts with conditional probability. We do not expect an interaction between the morphological function and conditional probability. Instead, we expect that both have independent effects on the segment and word duration.

\section{Methods}

\section{I Word material}

The material for the present study was extracted from the Phonetic Corpus of Estonian Spontaneous Speech (Lippus et al., 2020). The corpus consists of 180 face-to-face spontaneous conversations between two speakers, who were acquainted with each other. The corpus contains speech from 143 different speakers (some of them were recorded more than once). There are 78 female speakers and 65 male speakers (mean age $=41.20$ years, ranging from 20 to 85 years). The corpus contains approximately 90 hours of speech, therein included roughly 500,000 word tokens. The conversations were recorded in a sound booth or in a quiet room. Each conversation is approximately 30 minutes long. Words, segments and their boundaries were manually annotated in Praat (Boersma \& Weenink, 2021). The corpus is annotated with the following information: (1) phonetic transcription of the pronunciation using the Speech Assessment Methods Phonetic Alphabet (SAMPA) transcription, (2) orthographic spelling of the dictionary word form, (3) part-of-speech and morphological information of the form, and (4) syllable information. For the analysis, we extracted all content words (nouns, verbs, and adjectives) from the corpus that end in $/-\mathrm{s} /$. We excluded proper names and compounds.

As the aim of the present study is to investigate the variability of segment and word duration related to morphology, we attempted to minimize all other possible factors that could influence this 
variability. As discussed above, Estonian words vary strongly in their number of syllables, which typically affects segment duration (Altmann, 1980; Menzerath, 1928). To better control for variation in duration due to word length, we included only two-syllable words where the word-final segment was a short/-s/ preceded by a vowel. Focusing on disyllabic words kept the stress consistently on the first syllable. Also, a focus on disyllabic words minimizes the variability in syllable structure. The final data set consisted of 5,794 word tokens.

In the next subsection, we provide a summary of the dependent and independent variables considered in the analysis. The code and the data for the analysis are available as supplementary materials at https://osf.io/EX56H/.

\section{Analysis}

Below we list the dependent and independent variables we tested. In some cases, model fitting suggested that a particular variable was not significant, which in turn was not included in the final models presented in the "Results" section. We have indicated in the paragraphs below when a particular variable was not included in the final models.

\section{I Dependent variables}

The dependent variables were word duration (Study 1) and word-final/-s/ segment duration (Study 2) in seconds. Too make the work directly comparable with previous studies in morphophonetics that have concentrated on the segmental level (e.g., Plag et al., 2017; Seyfarth et al., 2018) and also with our previous work on word durations (Lõo, Järvikivi, Tomaschek, et al., 2018), we investigate both segment and word durations. We expect both dependent variables to behave the same way.

\subsection{Predictors}

We were interested in three types of predictors: inflectional function, inflectional paradigm size, and conditional probability.

Inflectional function: Initially, the word material was grouped into four categories according to the morphological function of the last segment: (a) monomorphemic stems without a derivational or inflectional affix ( $N=323$, e.g., lammas "sheep, nominative singular"); (b) derivational stems without an inflectional ending ( $N=737$, e.g., ilu-s "beautiful, nominative singular"); (c) inflected nouns and adjectives in inessive case $(N=2,347$, e.g., auto-s "in the car"); and (d) inflected verbs in the third-person singular past tense ( $N=2,266$, e.g., uju-s "he/she swam"). The distinction between category (a) and category (b) was based on the online version of the Estonian word families' dictionary (Vare, 2012).

During an initial exploratory analysis, it was established that the segment duration model including the morphological function as a predictor showed no significant differences between the $/$-s/ segment durations of derivational and monomorphemic words $(t=0.33, p=.74)$. As a result, we collapsed the words into two categories based on their inflectional properties: (a) inflected forms (4,653 words with inflectional affixes, i.e., categories (c) and (d) from above) and (b) uninflected forms (1,020 monomorphemic and derived words without an inflectional affix, i.e., categories (a) and (b) from above). Our predictor of interest was a binary category inflected/ uninflected. Model comparisons between the two models resulted in a better model fit for the model including the inflectional function predictor rather than the morphological function (fast restricted maximum likelihood estimation [fREML] = 13.11 lower, Akaike information criterion $[A I C]=8.61$ lower, see supplementary materials for this analysis). 
Our next predictor of interest is inflectional paradigm size: It gauges the number of observed inflected forms for a certain lemma from the Estonian spontaneous speech corpus. For example, for the lemma lammas "sheep," the paradigm size was four: lammas "nominative singular," lambad "nominative plural," lammastele "allative plural," and lambaid "partitive plural." Paradigm size varied between 1 and 40 (mean $=26.51$, median $=19)$ for the words in our data set. Comparisons between the smaller 0.5 million token corpus and a larger written Balanced Corpus of Estonian with 15 million tokens (Kaalep \& Muischnek, 2005) showed that the distribution of the inflectional paradigm size was similar. Thus, as it more closely reflects spoken language, we decided to estimate the inflectional paradigm size measure on the basis of the spoken corpus. Paradigm size was square root transformed to approximate a normal distribution.

The final predictor of interest is conditional probability: Following the work by A. Bell et al. $(2003,2009)$, we included conditional probability given the previous word and given the next word as predictors.

(a) The conditional probability of a particular word $w_{i}$ given a previous word $w_{i-1}$ was estimated by counting the instances of the two words occurring together $C\left(w_{i-1} w_{i}\right)$ in the Estonian spontaneous speech corpus and dividing this number by the total number of times the previous word occurred in the corpus.

$$
P\left(w_{i} \mid w_{i-1}\right)=\frac{C\left(w_{i-1} w_{i}\right)}{C\left(w_{i-1}\right)}
$$

(b) The conditional probability of a particular word $w_{i}$ given the next word $w_{i+1}$ was estimated by counting the instances where the current and the next word occur together $C\left(w_{i} w_{i+1}\right)$ and dividing this by the total number of times the next word occurred in the corpus $C\left(w_{i+1}\right)$ :

$$
P\left(w_{i} \mid w_{i+1}\right)=\frac{C\left(w_{i} w_{i+1}\right)}{C\left(w_{i+1}\right)}
$$

$\mathrm{P}\left(w_{i} \mid w_{i-1}\right)$ varied between 0.0000179 and 1 for our words (mean $=0.153$, median $\left.=0.006\right) . \mathrm{P}$ $\left(w_{i} \mid w_{i+1}\right)$ varied between 0.0000256 and $1($ mean $=0.071$, median $=0.0015)$. Due to the relatively small size of the corpus, some words occurred only once, and have therefore a conditional probability of 1. Conditional probabilities were log-transformed to approximate a normal distribution. Similar to A. Bell et al. (2009), we found that only P $\left(w_{i} \mid w_{i+1}\right)$ but not P $\left(w_{i} \mid w_{i-1}\right)$ was a significant predictor for content words and only the former was included in the final models.

\subsection{Control variables}

Based on the previous research and the specifics of Estonian phonology, we also considered several control variables.

3.3. I Frequency. It has been well established that more frequent words are articulated with shorter durations (Whalen, 1991; Wright, 1979). While models of speech production assume that wholeword properties of morphologically complex words should not co-determine production characteristics (Levelt et al., 1999; Roelofs, 1997), numerous studies challenge this assumption. For example, Caselli et al. (2016) studied frequency effects in English conversational speech. They 
found that acoustic durations of inflected forms decreased with increasing whole-word frequency. This effect was present even when the stem frequency was controlled for (see also Lõo, Järvikivi, Tomaschek, et al., 2018). Plag et al. (2020) found that whole-word frequency reduced acoustic durations of complex words in English, even when the stem frequency was equal. To account for these effects, in this study, we considered two different frequency measures as control variables: (a) Whole-word frequency captures the total number of occurrences of a particular form in the spontaneous speech corpus. Whole-word frequency varied between 1 and 446 (mean=106.7, median=26) for the words in our data set. (b) Lemma frequency is the cumulative frequency of a complete inflectional paradigm. Lemma frequency varied between 1 and 2,899 (mean=459, median $=176$ ) for the words in our data set. Both were calculated from the spontaneous speech corpus and log-transformed.

3.3.2 Number of segments. Words with more segments are also articulated with longer duration. For segment duration in words, the finding is the opposite, in longer words each individual segment is shorter (Menzerath, 1954). In this analysis, the number of segments was calculated by counting the number of segments in the dictionary form of the word.

3.3.3 Neighborhood density. It has been shown that words with a large number of phonological neighbors are articulated with shorter durations than words with a small number of phonological neighbors (Gahl et al., 2012), for example. In this study, we calculated phonological neighborhood density based on the dictionary form of the word, by counting the words that differ in one segment from the word in question, using the R-package $v w r$ (Keuleers, 2013). Neighborhood density varied between 1 and $30($ mean $=9.3$, median $=8)$ for the words in our data set. Neighborhood density was not a significant predictor and hence not included in our final models.

3.3.4 Local speech rate. Previous research has shown that words spoken at a faster speech rate are produced with shorter durations (e.g., De Jong \& Wempe, 2009, and citations therein). We calculated the local speech rate by dividing the number of syllables in an actual pronunciation of an utterance by the duration of the utterance. The utterance was defined as an interpausal unit for example, the speech sequence between two pauses as coded by the manual annotator.

3.3.5 Voicing of the /-s/. Voicing has been shown to correlate with duration (e.g., Klatt, 1976). Unlike in many other languages, Estonian fricatives do not have a phonological voicing contrast (Asu \& Teras, 2009; Eek \& Meister, 1999). However, voiceless fricatives can be voiced when occurring in a voiced context (Ermus \& Mihkla, 2019). In this study, this was detected from the corpus annotation, which was done manually by the annotator. Decisions were made based on auditory perception and visual inspection of the sound wave and spectrogram.

3.3.6 Quantity. As described in Section 1.1., Estonian has a unique three-way quantity distinction. The following duration ratio distribution has been proposed for two-syllable words: 2:3 for the first quantity (Q1), 3:2 for the second quantity (Q2), and 2:1 for the third quantity (Q3) (Lehiste, 1960), with the ratios representing relative durations of the two syllables. Accordingly, while words in Q3 are expected to have the longest overall word duration, the word-final segment durations of Q3 words are expected be shorter than the word-final segment durations of Q1 and Q2 words.

In our data set, 959 words were in Q1 (kodus /kotus/ "home, inessive singular"), 1,937 in Q2 (katus /kattus/ "roof, nominative singular"), and 2,898 in Q3 (kattes /kat:tes/ "cover, inessive singular"). Quantity of the words was calculated automatically based on the manual annotations of the syllable structure and suprasegmental length. 
3.3.7 Manner. Klatt (1976) reported that the duration of segments is affected by the manner of articulation of the following segment, showing that the more the airflow of the following segment is obstructed, the shorter the given segment. This means that segments are produced longer when they are followed by a vowel or an approximant than when they are followed by a plosive or a fricative. We accounted for this by coding the manner of articulation of the initial consonant of the following word as: none, approximant, fricative, nasal, plosive, trill, vowel.

3.3.8 Part-of-speech. Previous research suggests that there are duration differences within content words depending on whether the word is a noun or a verb. For example, it has been shown that verbs are usually pronounced with shorter durations than nouns (e.g., Dilts, 2013; Gahl et al., 2012; Lohmann, 2018; Seyfarth, 2014).Our data set consisted of 2,967 nouns, 482 adjectives, and 2,345 verbs. Part-of-speech was not a significant predictor and hence not included in our final models.

3.3.9 Disfluency and pauses following. Previous research suggests that segments and words before and after pauses are lengthened in spontaneous speech (Byrd et al., 2006; Klatt, 1976).In Estonian, word-final lengthening in speech has been shown, for example, by Mihkla (2006) and Krull (1997). Disfluencies in Estonian have not been investigated so far. In this study, pauses and disfluencies in the preceding word did not significantly affect the duration and thus only disfluency and pause following the word were included. In our data set, 540 words were followed by a pause, and 896 words were followed by a disfluency, for example, false starts, words spoken with laughter, and so on. Pauses and disfluencies were hand-coded by the annotator.

3.3. 10 Age and gender of the speaker. Previous research indicates that males and younger speakers produce words with shorter duration than females and older speakers (A. Bell et al., 2009; Raymond et al., 2006; Simpson, 2009). Aare and Lippus (2017) studied gender and age effects in Estonian conversations, and found that articulation rate was faster for male speakers, but no age effect was found. Age and gender were not significant predictors and hence not included in the final models.

In the next sections, we report our modeling strategy and the results of our two analyses of word and segment duration.

\subsection{Modeling strategy}

Model fitting was conducted with generalized additive mixed models (GAMMs, Hastie \& Tibshirani, 1990; Wood, 2017; R-package $m g c v$, version 1.8). GAMMs have gained recent popularity in analyzing various types of linguistic data, such as electroencephalography (EEG) data (Tremblay \& Baayen, 2010), dialectometry (Wieling et al., 2011), reaction times (Feldman et al., 2015; Lõo, Järvikivi, \& Baayen, 2018), spoken word perception (Porretta et al., 2016), and also speech production (Kösling et al., 2013; Lõo, Järvikivi, Tomaschek, et al., 2018). Unlike linear mixed models (Baayen et al., 2008), GAMMs allow the testing of nonlinear interactions between the dependent and the predictor variable as well as between the predictor variables. The residuals of the final models were checked and they were normally distributed. No auto-correlation was detected in the residuals of the final models.

As high collinearity among predictors may result in false positives and false negatives (see, e.g., Tomaschek, Hendrix, \& Baayen, 2018), we carefully inspected the effects of collinearity in our models. First, we calculated the Spearman rank correlation between our numeric predictors and control variables. Table 2 shows that inflectional paradigm size, lemma frequency, and whole-word frequency were highly correlated with each other $\left(R^{2}>0.6\right)$. Second, we checked collinear 
Table 2. The Spearman Rank Correlation Coefficient Values of Continuous Variables.

\begin{tabular}{|c|c|c|c|c|c|c|c|c|}
\hline & $\begin{array}{l}\text { segm } \\
\text { dur }\end{array}$ & $\begin{array}{l}\text { word } \\
\text { dur }\end{array}$ & freq & $\begin{array}{l}\text { Lemma } \\
\text { freq }\end{array}$ & par size & $\begin{array}{l}\text { cond } \\
\text { prob }\end{array}$ & $\begin{array}{l}\mathrm{nr} \\
\text { segments }\end{array}$ & $\begin{array}{l}\text { speech } \\
\text { rate }\end{array}$ \\
\hline segm dur & -1.00 & & & & & & & \\
\hline word dur & -0.58 & 1.00 & & & & & & \\
\hline freq & -0.10 & -0.40 & 1.00 & & & & & \\
\hline lemma freq & -0.12 & -0.38 & 0.84 & 1.00 & & & & \\
\hline par size & -0.12 & -0.30 & 0.62 & 0.89 & 1.00 & & & \\
\hline cond prob & -0.28 & -0.37 & 0.26 & 0.25 & 0.21 & 1.00 & & \\
\hline $\mathrm{nr}$ segments & -0.05 & 0.29 & -0.16 & -0.15 & -0.07 & -0.08 & 1.00 & \\
\hline speech rate & -0.37 & -0.52 & 0.11 & 0.09 & 0.04 & 0.11 & -0.07 & 1.00 \\
\hline
\end{tabular}

Pairs with values over 0.6 are marked in bold. segm dur=segment duration; word dur= word duration; freq= wholeword frequency; lemma freq=lemma frequency; par size = inflectional paradigm size; cond prob = conditional probability; $\mathrm{nr}$ segment $=$ the number of segments in the word; speech rate=local speech rate of the utterance.

predictors both together and separately in the model to assess whether effects of suppression or enhancement between the correlated predictors arise (see, e.g., Friedman \& Wall, 2005). Suppressors and enhancers are variables that when added to a regression model, change the original relationship between the predictor and dependent variable by making it stronger, weaker, no longer significant, or by reversing the direction of the relationship.

Final models were obtained by pursuing an exploratory step-wise forward fitting modeling approach in which the contribution of each individual predictor was compared against the baseline model. This procedure was followed by a backward model fitting procedure to reassess each predictor's contribution. Random effects contained random intercepts for speakers and the manner of the first segment of the following words. Following Baayen et al. (2017), our models did not include any random slopes. Following the advice in the work of Baayen and Linke (2020), word as a random intercept was not included in the model to avoid to high concurvity/collinearity between random intercepts and fixed effects. As 795 words out of 5,794 (13.7\%) occur only once in the corpus, including random structure for words causes overfitting. Pairwise model comparisons were conducted using the fREML and AIC scores provided by the compareML function in the R-package itsadug (version 2.4) to select the best predictors.

Visual inspection of the distribution of word duration indicated that a few word tokens had very long durations, which is why we removed three data points $(0.05 \%)$ with word durations over 1 second. The mean word duration in the data set was 0.39 seconds and the standard deviation was 0.12 seconds. The final data set included 5,791 data points. Since we apply an exploratory approach to our data analysis, and to be more conservative about our interpretation of the effects, we set a $p$-value of .001 as the significance threshold for our study.

\section{Results}

\section{I Study I: word duration}

In the first study, we investigated effects in the acoustic duration of the whole word. Note that inflectional paradigm size was highly correlated with lemma frequency and moderately correlated with whole-word frequency (Table 2). Accordingly, paradigm size and frequency were tested both in the same and in the separate models to inspect for possible effects of suppression or enhancement due to correlation. This procedure found that the model including both inflectional paradigm 
Table 3. fREML Scores Representing Model Fits between the Baseline Model and Models Including Each Individual Predictor in the Word Duration Analysis.

\begin{tabular}{lc}
\hline Model & fREML score \\
\hline Baseline & $-1,000.67$ \\
+ Inflectional function & -817.48 \\
+ Inflectional paradigm size & $-1,093.68$ \\
+ Conditional probability & $-1,168.81$ \\
\hline
\end{tabular}

Table 4. Summary of the GAMM Model Fitted to the Log-Transformed Word Duration.

\begin{tabular}{|c|c|c|c|c|}
\hline A. Parametric coefficients & Estimate & Std. error & $t$ value & $p$ value \\
\hline (Intercept) & -1.4829 & 0.0297 & -49.8849 & $<.000 I^{*}$ \\
\hline Number of segments & 0.0801 & 0.0051 & 15.7089 & $<.000 I^{*}$ \\
\hline Quantity 2 & -0.0040 & 0.0101 & -0.3999 & .6893 \\
\hline Quantity 3 & 0.0327 & 0.0099 & 3.2869 & $.0010 *$ \\
\hline Disfluency following & 0.1449 & 0.0081 & 17.9403 & $<.000 I^{*}$ \\
\hline Pause following & 0.1425 & 0.0111 & $|2.797|$ & $<.000 I^{*}$ \\
\hline $\mid$-s $/=$ inflected & -0.0150 & 0.0078 & -1.9113 & .0560 \\
\hline B. Smooth terms & Edf & Ref. $d f$ & $F$ value & $p$ value \\
\hline s (speech rate) & 4.9655 & 6.0949 & 199.1948 & $<.000 I^{*}$ \\
\hline s (log conditional probability) & 2.9521 & 2.9978 & 60.0801 & $<.000 I^{*}$ \\
\hline s (log frequency) & 5.2512 & 6.2708 & 52.3642 & $<.000 I^{*}$ \\
\hline s (sqrt paradigm size) & 2.8672 & 2.9851 & $50.654 I$ & $<.000 I^{*}$ \\
\hline$s$ (next manner) & 4.4034 & 5.0000 & 19.3659 & $<.000 I^{*}$ \\
\hline s (speaker) & 116.6102 & 141.0000 & 6.6573 & $<.000 I^{*}$ \\
\hline
\end{tabular}

*Significance threshold is set to $0.000 \mathrm{I}$.

size and whole-word frequency provided lower $f R E M L$ and $A I C$ scores compared to a model with only whole-word frequency $(f R E M L=68.97, A I C=156.74$ lower $)$, a model with only inflectional paradigm size $(f R E M L=58.20, A I C=122.44$ lower $)$, or a model with only lemma frequency $(f R E M L=85.46, A I C=164.10$ lower $)$.

As a consequence, we selected both inflectional paradigm size and whole-word frequency as predictors in our final model. As can be seen from Table 3, including inflectional function to the model did not improve the model fit. By contrast, the inclusion of paradigm size and conditional probability improved the model fit considerably. However, to keep the variables of interest in both studies comparable, we kept inflectional function in the model. The summary of the final model for word duration is outlined in Table 4, and the effects are illustrated in Figure 1.

Number of segments, frequency, speech rate, and quantity emerged as significant control variables in the model. As can be seen in Table 4, words with more segments were produced with longer duration than words with fewer segments. Words in the third quantity were produced with longer duration than in the first quantity. However, there was no significant difference between the words in the first and second quantity. Words with a following pause or disfluency were produced with longer durations than words without a following pause or disfluency. Finally, word durations decrease as speech rate and frequency increase (see supplementary materials for plots). In conclusion, the effects of the control variables pointed to the expected direction. 


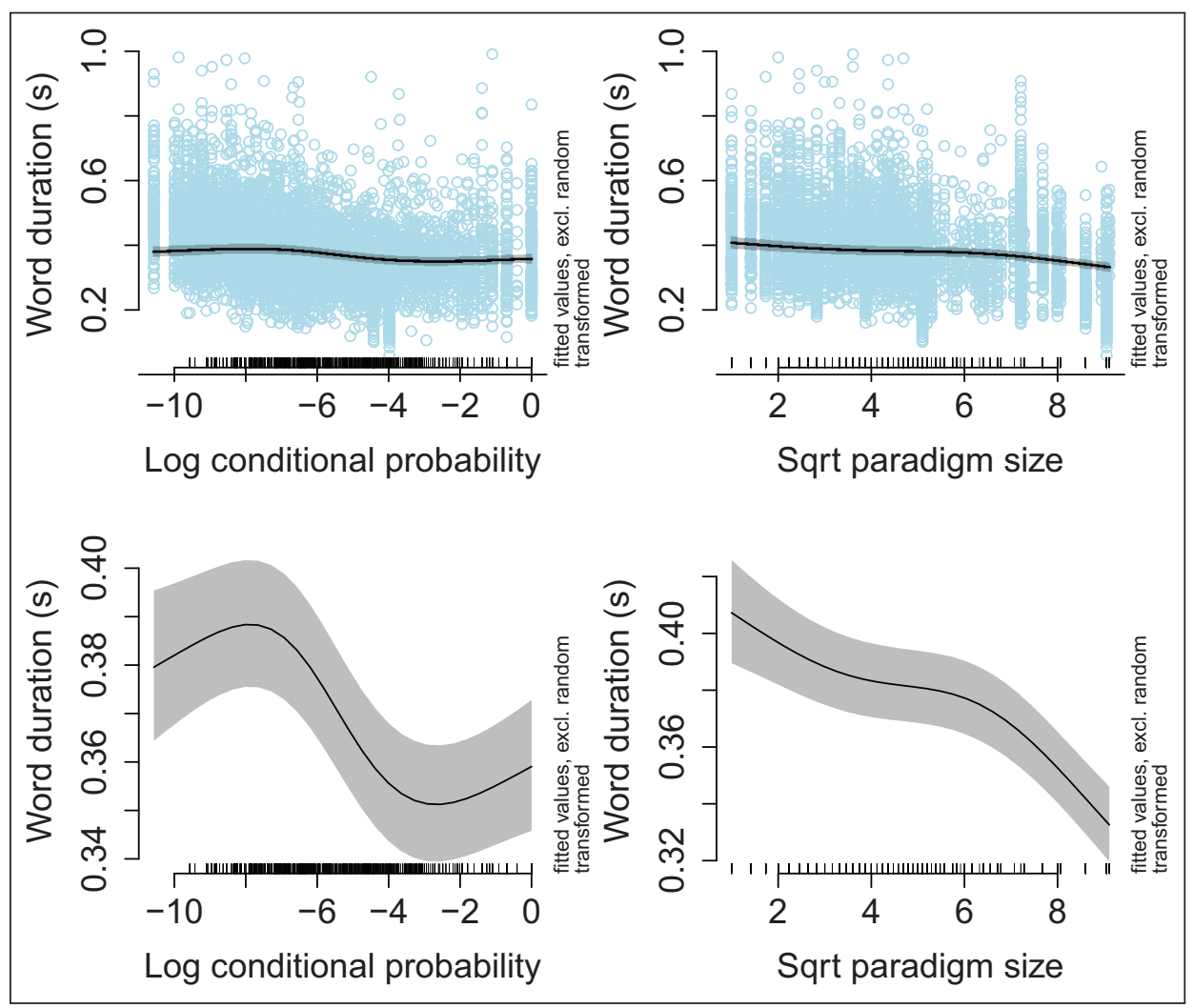

Figure I. Estimated effects of conditional probability and inflectional paradigm size on word duration (Study I).

The figures in the upper row contain light blue dots that represent the individual data points, the rug below the panels shows how the data are distributed. The gray shadows represent $95 \%$ confidence bands $(S E=1.96)$ of the black regression line for conditional probability and inflectional paradigm size on word duration. The lower row illustrates the same results as illustrated in the upper row but with a restricted $y$-axis to give the reader a better sense of the effects. The scale for the $y$-axis was back-transformed to seconds.

Next, we turn our attention to our variables of interest - inflectional function, realized inflectional paradigm size, and conditional probability. Inflected forms were not significantly shorter than uninflected forms $(p=.055)$. Figure 1 illustrates the effects of conditional probability and inflectional paradigm size on word duration. To illustrate both the data and the estimated smooth, we have provided two versions of Figure 1. The upper row of the figure is a scatter plot of the individual data points extracted from the corpus, with the partial effect of the model fit plotted on top of the scatter plot. When plotting the results this way, the nonlinear effects are difficult to see. These become more visible at the bottom row of Figure 1 which shows the partial effect with a $y$-axis restricted on the scale of the effect.

The left panels of Figure 1 illustrate the smooth of conditional probability; as predicted the more probable words have shorter durations. For very low and high conditional probability, the effect seems to level off, though we note that the model is less confident at the edges of the distribution. This is likely due to sparse data for very low and high conditional probability words and potential edge effects (Hastie \& Tibshirani, 1990). The right panels in Figure 1 indicate that greater inflectional paradigm size is associated with shorter word durations. The effect in the first two quantiles 
Table 5. fREML Scores Representing Model Fits between the Baseline Model and Models Including Each Individual Predictor in the Segment Duration Analysis.

Model

fREML score

Baseline

$\mathrm{I}, 180.32$

+ Inflectional function

$1,177.20$

+ Inflectional paradigm size

$1,167.26$

+ Conditional probability

$1,158.04$

+ Conditional probability: inflectional function

$1,156.81$

is less steep than in the last two quantiles of paradigm size. We also tested interactions between all variables of interest, but none yielded any significance.

\subsection{Study 2: segment duration}

In the second analysis, we investigated the effects on segment duration.

We followed the same fitting procedure as in Study 1. Testing the effect size of our predictors of interest, we found that inflectional paradigm size yielded lower $f R E M L$ and $A I C$ scores than whole-word frequency (fREML $=15.32$ lower and $A I C=47.09$ lower) or lemma frequency ( $f R E M L=13.91$ lower, $A I C=43.98$ lower). When inflectional paradigm size and frequency were fitted in the same model, frequency lost significance which is why it was not included in the final model.

As in Study 1, we tested the contribution of each individual predictor against a baseline model. Table 5 shows that the inclusion of inflectional function improved the model fit slightly. The inclusion of inflectional paradigm size improved the model fit. Including an interaction between the inflectional function and conditional probability resulted in the best model fit.

All control predictors yielded significant effects in the expected direction (Table 6). Words with more segments were produced with a shorter final segment than words with fewer segments. Utterances with a higher speech rate resulted in shorter final/-s/ segments than utterances with a lower speech rate (see supplementary materials for the plot). Words in the second and in the third quantity were produced with a shorter final segment duration compared to words in the first quantity. Voiced /-s/ was produced shorter than voiceless /-s/, and finally, segments with a following disfluency or pause were articulated with longer durations than segments without a following disfluency or pause.

Turning our attention to our variables of interest, we found that inflectional paradigm size yielded a significant linear effect, with shorter segment durations associated with increasing inflectional paradigm size. No significant interaction between inflectional function and inflectional paradigm size was found.

As for inflectional function, it did not yield any significant effect as a main predictor $(p=.03)$. However, it significantly interacted with conditional probability with the smooths yielding significant effects whenever/-s/ reflected an inflectional function.

The effects of our significant predictors of interest are illustrated in Figure 2. For better clarity, the figure illustrates the raw data as a scatter plot including the smooth (top) and the estimated smooth (bottom) with the $y$-axis restricted to the size of the effect. The left panels of Figure 2 show that higher conditional probability was associated to shorter duration of inflected /-s/. The right panels illustrate that higher inflectional paradigm size was associated to shorter duration of /-s/, independently of its inflectional status. An interaction between conditional probability and inflectional paradigm size was also tested, but it was not significant. 
Table 6. Summary of GAMM Model Fitted to the Log-Transformed Word-Final /-s/ Segment Duration.

\begin{tabular}{|c|c|c|c|c|}
\hline A. Parametric coefficients & Estimate & Std. error & $t$ value & $p$ value \\
\hline (Intercept) & -2.2945 & 0.0463 & -49.5871 & $<.000 I^{*}$ \\
\hline Number of segments & -0.0305 & 0.0075 & -4.0879 & $<.0001 *$ \\
\hline Quantity 2 & -0.0480 & 0.0146 & -3.2796 & $.0010 *$ \\
\hline Quantity 3 & -0.0882 & 0.0143 & -6.1711 & $<.000 I^{*}$ \\
\hline Voicing: voiced & -0.2789 & 0.0144 & -19.3996 & $<.0001 *$ \\
\hline Disfluency following & 0.3059 & 0.0122 & $25.148 \mid$ & $<.000 I^{*}$ \\
\hline Pause following & 0.3464 & 0.0158 & 21.8767 & $<.000 I^{*}$ \\
\hline$/-s /=$ inflected & -0.0246 & 0.0115 & -2.1333 & .0329 \\
\hline sqrt paradigm size & -0.0079 & 0.0021 & -3.6812 & $.0002 *$ \\
\hline B. Smooth terms & edf & Ref. df & $F$ value & $p$ value \\
\hline s (log conditional probability):/-s/ = uninflected & 1.0001 & 1.0001 & 1.3442 & .2464 \\
\hline s (log conditional probability):/-s/= inflected & 1.2568 & 1.4642 & 34.1459 & $<.000 I^{*}$ \\
\hline s (speech rate) & 3.7487 & 4.7250 & $|46.50| 4$ & $<.000 I^{*}$ \\
\hline s (next manner) & 4.5313 & 5.0000 & 26.0824 & $<.000 I^{*}$ \\
\hline s (speaker) & 99.7612 & $|4| .0000$ & 3.3183 & $<.000 I^{*}$ \\
\hline
\end{tabular}

*Significance threshold is set to $0.000 \mathrm{I}$.

\section{Discussion}

The present study investigated the effect of word-internal and word-external morphological and structure on the phonetic duration of Estonian words (Study 1) and word-final/-s/ (Study 2), while controlling for predictability in syntagmatic contexts.

First, unlike recent work by Plag et al. (2017) and subsequent replications, word-final /-s/ in inflected position was not shorter than word-final /-s/ in uninflected position. A systematic difference between inflected and uninflected /-s/ emerged, however, in an interaction with conditional probability of the target word given the following word: higher conditional probability was associated with shorter/-s/ durations only for inflected word forms. Also, unlike for English (Plag et al., 2020), we did not find differences in word duration depending on the inflectional function of the word-final /-s/.

Second, we found that smaller inflectional paradigm size (i.e., smaller number of realized inflected forms in the spontaneous speech corpus) was associated with longer word durations and word-final /-s/ durations. This finding extends the work presented in Lõo, Järvikivi, Tomaschek, et al. (2018), which reported paradigmatic effects in Estonian single word production. This supports the paradigmatic enhancement hypothesis, which argues that stronger paradigmatic support leads to longer acoustic durations in speech (Kuperman et al., 2007).

The current findings indicate that paradigmatic effects pertain even when the syntagmatic context of the word is accounted for in spontaneous speech. Critically, the paradigm effect and conditional probability effect do not interact in our analysis, but rather emerge as main effects. This suggests that they play an independent role in speech production. The null effect of inflectional function but pertaining paradigmatic effects suggest that word-external morphological structures rather than word-internal structures influence the production of Estonian.

These results of inflectional paradigm size for word and segment durations indicate that paradigmatic effects emerge for Estonian like they do for morphologically less complex languages, 


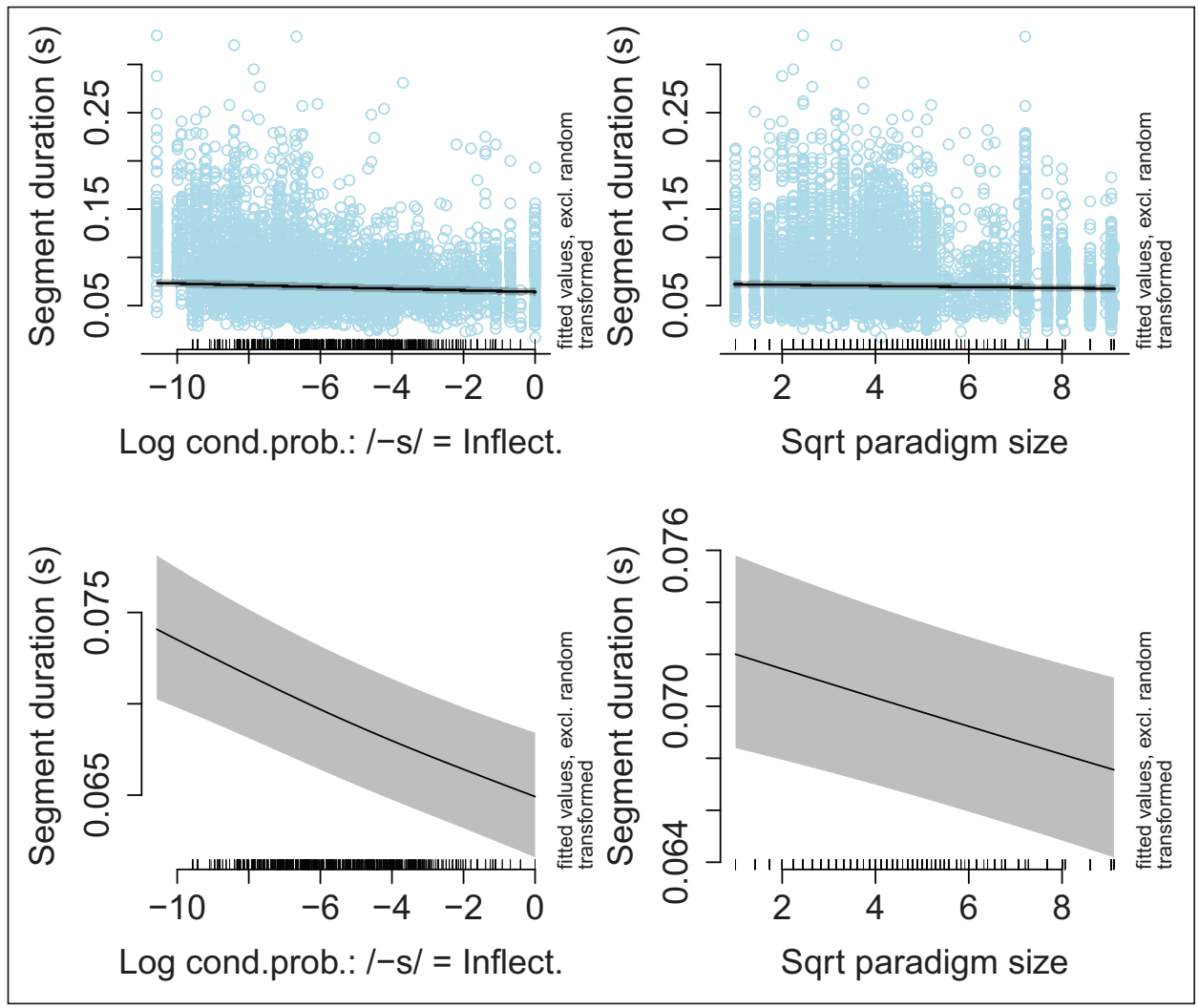

Figure 2. Estimated effects of conditional probability and inflectional paradigm size for /-s/ duration (Study 2).

The upper row figures contain the light blue dots which represent the individual data points, and the rug below the panels shows how the data are distributed. The gray shadows represent $95 \%$ confidence bands $(S E=1.96)$ of the regression line for individual predictors on /-s/ duration. The lower row illustrates the same results as illustrated in the upper row but with a restricted $y$-axis. The $y$-axis was back-transformed to seconds.

such as Dutch or English (M. J. Bell et al., 2021; Kuperman et al., 2007). For example, M. J. Bell et al. (2021) reported shorter durations of linking consonants in compounds in relation to the larger morphological family size. They argue that larger family size is equivalent to lower paradigmatic probability, and smaller family size is equivalent to higher paradigmatic probability. Higher paradigmatic probability has been repeatedly also shown to be associated with phonetic enhancement in other studies (e.g., Cohen, 2014, 2015; Tily \& Kuperman, 2012; Tomaschek et al., 2021).

However, while in English, most word forms in a paradigm have a relatively high probability of being actively used - especially in inflected and high frequency words - this is not the case in Estonian. This is reflected by different sizes of realized inflectional paradigms (e.g., jalg "foot" vs. lammas "sheep," see Section 1.3.). In comparison to languages with relatively small inflectional paradigms, such as English, there are some forms in Estonian paradigms that are rarely used in everyday communication. This has implications for the amount of experience speakers have with words in individual paradigms. The present results suggest that the Estonian production system is tuned to the distributional characteristics of the language. Importantly, this result is dependent on a paradigm size measure reflecting actual language usage, that is., the realized inflectional 
paradigm, not a theoretical paradigm size measure as this measure would be very similar for all words.

In a same way that articulatory patterns correlate with phonological neighborhood density effects (Scarborough, 2013; Taft \& Hambly, 1986), the inflectional paradigm size effect indicates that when a word is produced, all actively used members of a paradigm are activated during production. Cohen (2015) explains such effects through exemplar theory (Goldinger, 1998; Pierrehumbert, 2001). She suggests that a simultaneous activation of multiple plausible words within a paradigm is possible.

Critically, we see the effect of paradigm size as independent of phonological neighborhood density, because the latter did not yield a significant effect in our analyses. The present findings of paradigmatic effects on the segmental level, replicate those by Cohen (2015), who found paradigmatic effects in the presence of syntagmatic effects for Russian vowel suffixes in laboratory speech. We provide two possible explanations for the observed shortening of /-s/ associated with larger paradigmatic families.

First, it may simply result from stronger activation of the targeted word form due to the activation of the paradigm. Second, articulatory gestures of the target word may benefit from the experience that speakers have gained while articulating other word forms from the paradigm (Bybee \& Hopper, 2001; Tomaschek, Tucker, et al., 2018). Larger paradigmatic families yield increased articulatory practice which allows for faster and stronger overlapped articulatory gestures, resulting in shorter phonetic durations. However, as inflectional paradigm effects have been shown to reflect reaction times in lexical decision and word naming tasks as well (Lõo, Järvikivi, \& Baayen, 2018; Lõo, Järvikivi, Tomaschek, et al., 2018), the practice account cannot at least fully account for the results.

In addition to replicating the effect of realized inflectional paradigm size on segment and word duration, we also replicate the well documented effect of conditional probability for Estonian. As previously found for many other languages (e.g., English: A. Bell et al., 2009, Dutch: Tily \& Kuperman, 2012, and Kaqchikel: Tang \& Bennett, 2018), words in more probable contexts were produced with shorter durations than words in less probable contexts. We show an unexpected finding for the correlation between segment duration and conditional probability of the target word given the following word. We find that only inflected /-s/ but not uninflected /-s/ correlates with conditional probability. It is possible that this effect arises because these two instances differ in terms of the probability of their function. The inflected/-s/ conveys an inflectional function, while the uninflected /-s/ is simply part of the base. As the inflectional function may be recovered on the basis of the following word, it is sensitive to predictability. This explanation dovetails with the findings by Torreira and Ernestus (2012), who reported variable effects of devoicing depending on the informativity of the inflectional function for word-final/-s/ in Spanish. However, given the current data, no definitive explanation is possible.

The present findings regarding the role of morphology in Estonian speech production also have implications for models and theories of speech production (see Tucker, 2019, for a review). For example, in Levelt et al.'s (1999) top-down theory of word production, the articulation level does not have information about the inflectional function of the word, thus it is in line with our current findings of null effect of inflectional function. However, their model could not explain the effect of inflectional function interacting with conditional probability and the fact that duration differences according to their morphological function have been widely found for English (e.g., Plag et al., 2017; Seyfarth et al., 2018).In order for their model to be able to predict such an effect, the articulation level needs to have access to information processed at the morpheme level. Such a process was implemented by Dell (1986). However, it has not been tested as Dell's model did not use morphologically complex words in his simulations. 
Recent production literature suggests that there are two types of models that could potentially explain the morphological effects found in this paper. These are exemplar models (Goldinger, 1998; Pierrehumbert, 2001) and discriminative learning models (Baayen et al., 2011, 2019; Ramscar, 2021; Ramscar et al., 2010). Although these frameworks differ in terms of how the knowledge in the mental lexicon is learned and used, they both assume the lexicon stores complex pieces of information - from fine acoustic detail of individual words to their syntagmatic and situational context which defines their semantics. The question thus arises why the duration differences attested by Plag et al. (2017) and numerous following studies did not directly emerge in Estonian.

One possible explanation may be in the number of inflectional functions that /-s/ has in the different languages. In English, word-final /-s/ has seven functions (third-person singular, plural, genitive, genitive plural, is and has clitic). By contrast, in Estonian, /-s/ has only two main functions. Word-final /-s/ serves as a location marker for nouns (auto-s "in the car") and a past tense marker for verbs (uju-s "swam"). Thus, it seems the functional load for /-s/ in Estonian is lower than for /-s/ in English. This tentative explanation is supported by the null effect of morphological function that has been attested in pluralia tantum versus regular plural/-s/ in English (Schlechtweg \& Corbett, 2021).

While Chuang et al. (2020) demonstrated that models allowing complex representations, such as discriminative learning, are capable to produce morphologically complex word forms within the written single word domain in Estonian, future studies will have to investigate to what degree they also correctly predict the differences in duration attested in the present spontaneous speech study.

\section{Conclusion}

In summary, our study showed that decreasing realized inflectional paradigm size increased the duration of words and segments under investigation. Increasing conditional probability decreased both segment and word duration in the production of Estonian spontaneous speech, but for word duration, there was no effect for either especially high or low probabilities, though this may have been an effect of data sparseness. On the segmental level, conditional probability interacted with the inflectional function, in such a way that increasing conditional probability only decreased the duration of the inflectional /-s/.

The current research suggests that language-specific distributional patterns of language usage affect the production of spontaneous speech. Whereas for English, the duration of /-s/ has been shown to vary depending on its function, for Estonian, it does not. What seems to matter in Estonian production is the realized inflectional paradigm of the language that is usage-based word-external morphological structures. Importantly, and similar to the work of Kuperman et al. (2007), who also found effects for morphological families within syntagmatic context, we report that even when syntagmatic context is present and even when only one or a few paradigmatic members are plausible in the given context, all realized paradigm members matter for Estonian production.

\section{Acknowledgements}

The authors would like to thank the editor and the reviewers for their very helpful comments on previous versions of the paper.

\section{Funding}

The author(s) disclosed receipt of the following financial support for the research, authorship, and/or publication of this article: This research was funded by the Mobilitas Pluss postdoctoral researcher grant (grant no. 
MOBJD408), the Estonian Research Council grant (grant no. PSG743), and by a collaborative grant from the Deutsche Forschungsgemeinschaft (German Research Foundation: Spoken Morphology, Projects BA 3080/3-2).

\section{ORCID iDs}

Kaidi Lõo (iD https://orcid.org/0000-0002-4536-5287

Fabian Tomaschek (iD) https://orcid.org/0000-0003-2246-663X

Benjamin V. Tucker (iD https://orcid.org/0000-0001-8965-7890

\section{Supplemental material}

Supplemental material for this article is available online.

\section{References}

Aare, K., \& Lippus, P. (2017). Some gender patterns in Estonian dyadic conversations. In Nordic prosody. Proceedings of the XIIth conference, Trondheim Ed. Abrahamsen, Jardar Eggesbö; Koreman, Jacques; van Dommelen, Wim. Frankfurt am Main: Peter Lang Publishers. (pp. 29-38).

Altmann, G. (1980). Prolegomena to Menzerath's Law. Glottometrika, 2, 1-10.

Asu, E. L., Lippus, P., Pajusalu, K., \& Teras, P. (2016). Eesti keele hääldus. Tartu Ülikooli kirjastus.

Asu, E. L., \& Teras, P. (2009). Estonian. Journal of the International Phonetic Association, 39(3), 367-372.

Aylett, M., \& Turk, A. (2004). The smooth signal redundancy hypothesis: A functional explanation for relationships between redundancy, prosodic prominence, and duration in spontaneous speech. Language and Speech, 47, 31-56.

Aylett, M., \& Turk, A. (2006). Language redundancy predicts syllabic duration and the spectral characteristics of vocalic syllable nuclei. Journal of the Acoustical Society of America, 119(5), 3048-3058.

Baayen, R. H., Chuang, Y.-Y., Shafaei-Bajestan, E., \& Blevins, J. P. (2019). The discriminative lexicon: A unified computational model for the lexicon and lexical processing in comprehension and production grounded not in (de) composition but in linear discriminative learning. Complexity, 2019, Article 4895891.

Baayen, R. H., Davidson, D. J., \& Bates, D. (2008). Mixed-effects modeling with crossed random effects for subjects and items. Journal of Memory and Language, 59, 390-412.

Baayen, R. H., \& Linke, M. (2020). An introduction to the generalized additive model. In S. T. Gries \& M. Paquot (Eds.), A practical handbook of corpus linguistics. Springer (pp. 563-591).

Baayen, R. H., Milin, P., Filipovic Durdjevic, D., Hendrix, P., \& Marelli, M. (2011). An amorphous model for morphological processing in visual comprehension based on naive discriminative learning. Psychological Review, 118(3), 438-481.

Baayen, R. H., Vasishth, S., Bates, D., \& Kliegl, R. (2017). The cave of shadows. addressing the human factor with generalized additive mixed models. Journal of Memory and Language, 56, 206-234.

Baker, R., Smith, R., \& Hawkins, S. (2007). Phonetic differences between mis-and dis-in English prefixed and pseudo-prefixed words. In Proceedings of ICPhS XVI Trouvain, J. and Barry, W.J. (Eds.), Proceedings of the 16th International Congress of Phonetic Sciences: ICPhS XVI, 6 - 10 August 2007, Saarbrücken, Germany. Universität des Saarlandes: Saarbrücken, Germany (pp. 553-556).

Bell, A., Brenier, J. M., Gregory, M., Girand, C., \& Jurafsky, D. (2009). Predictability effects on durations of content and function words in conversational English. Journal of Memory and Language, 60(1), 92-111.

Bell, A., Jurafsky, D., Fosler-Lussier, E., Girand, C., Gregory, M., \& Gildea, D. (2003). Effects of disfluencies, predictability, and utterance position on word form variation in English conversation. Journal of the Acoustical Society of America, 113, 1001-1024.

Bell, M. J., Hedia, S. B., \& Plag, I. (2021). How morphological structure affects phonetic realisation in English compound nouns. Morphology, 31, 87-120.

Boersma, P., \& Weenink, D. (2021). Praat: Doing phonetics by computer. http://www.praat.org 
Bybee, J. L. (2001). Phonology and language use. Cambridge University Press.

Bybee, J. L., \& Hopper, P. J. (2001). Frequency and the emergence of linguistic structure (Vol. 45). John Benjamins Publishing.

Byrd, D., Krivokapic, J., \& Lee, S. (2006). How far, how long: On the temporal scope of prosodic boundary effects. The Journal of the Acoustical Society of America, 120(3), 1589-1599.

Caselli, N. K., Caselli, M. K., \& Cohen-Goldberg, A. M. (2016). Inflected words in production: Evidence for a morphologically rich lexicon. The Quarterly Journal of Experimental Psychology, 69(3), 432-454.

Cho, T. (2001). Effects of morpheme boundaries on intergestural timing: Evidence from Korean. Phonetica, $58,129-162$.

Cho, T. (2004). Prosodically conditioned strengthening and vowel-to-vowel coarticulation in English. Journal of Phonetics, 32(2), 141-176.

Chuang, Y.-Y., Lõo, K., Blevins, J. P., \& Baayen, R. H. (2020). Estonian case inflection made simple: A case study in word and paradigm morphology with linear discriminative learning. In L. Kortvelyessy \& P. Stekauer (Eds.), Complex words: Advances in morphology (pp. 114-119). Cambridge University Press.

Cohen, C. (2014). Probabilistic reduction and probabilistic enhancement: Contextual and paradigmatic effects on morpheme pronunciation. Morphology, 24(4), 291-323.

Cohen, C. (2015). Context and paradigms: Two patterns of probabilistic pronunciation variation in Russian agreement suffixes. The Mental Lexicon, 10(3), 313-338.

De Jong, N. H., \& Wempe, T. (2009). Praat script to detect syllable nuclei and measure speech rate automatically. Behavior Research Methods, 41(2), 385-390.

Dell, G. (1986). A spreading-activation theory of retrieval in sentence production. Psychological Review, 93, 283-321.

Dilts, P. (2013). Modelling phonetic reduction in a corpus of spoken English using random forests and mixedeffects regression. University of Alberta.

Drosdowski, G., \& Eisenberg, P. (1998). Duden, Grammatik der deutschen Gegenwartssprache [Duden, Grammar of Contemporary German]. Dudenverlag.

Eek, A., \& Meister, E. (1999). Estonian speech in the babel multi-language database: Phonetic-phonological problems revealed in the text corpus. Proceedings of LP, 98(2), 529-546.

Erelt, M., Erelt, T., Viks, Ü., Kasik, R., Metslang, H., Rajandi, H., Ross, K., Saari, H., Tael, K., \& Vare, S. (1995). Eesti keele grammatika. 1., Morfoloogia sõnamoodustus [Grammar of Estonian Language 1., Morphology and Word Formation]. Eesti TA Keele ja Kirjanduse Instituut.

Erelt, T., Leemets, T., Mäearu, S., \& Raadik, M. (2018). Eesti õigekeelsussõnaraamat: ÕS 2018 [The Dictionary of Standard Estonian: ÕS 2018]. Eesti Keele Sihtasutus.

Ermus, L., \& Mihkla, M. (2019). Predictability of plosive reduction from written text in Estonian. In S. Calhoun, P. Escudero, M. Tabain, \& P. Warren (Eds.), Proceedings of the 19th International Congress of Phonetic Sciences, Melbourne, Australia 2019 (pp. 2635-2639). Australasian Speech Science and Technology Association.

Feldman, L. B., Milin, P., Cho, K. W., del Prado Martín, F. M., \& O'Connor, P. A. (2015). Must analysis of meaning follow analysis of form? A time course analysis. Frontiers in Human Neuroscience, 9, Article 111.

Friedman, L., \& Wall, M. (2005). Graphical views of suppression and multicollinearity in multiple regression. The American Statistician, 59, 127-136.

Gahl, S., Yao, Y., \& Johnson, K. (2012). Why reduce? phonological neighborhood density and phonetic reduction in spontaneous speech. Journal of Memory and Language, 66(4), 789-806.

Goldinger, S. D. (1998). Echoes of echoes? An episodic theory of lexical access. Psychological Review, 105(2), 251-279.

Gregory, M., Raymond, W., Bell, A., Fosler-Lussier, E., \& Jurafsky, D. (1999). The effects of collocational strength and contextual predictability in lexical production. CLS, 35, 151-166.

Hamm, J. (1981). Grammatik der serbokroatischen Sprache (Slavische Studienbücher. 5) [Serbo-Croatian Grammar vol. 5]. Harrassowitz.

Hastie, T., \& Tibshirani, R. (1990). Generalized additive models. Chapman \& Hall.

Hay, J. B. (2003). Causes and consequences of word structure. Routledge. 
Jurafsky, D., Bell, A., \& Gyrand, C. (2002). The role of the lemma in form variation. In C. Gussenhoven \& N. Warner (Eds.), Papers in laboratory phonology VII (pp. 1-34). Mouton de Gruyter.

Kaalep, H.-J., \& Muischnek, K. (2005). The corpora of Estonian at the University of Tartu: The current situation. In M. Langemets \& P. Penjam (Eds.), Proceedings of the Second Baltic Conference on Human Language Technologies (pp. 267-272).

Karlsson, F. (1986). Frequency considerations in morphology. STUF-Language Typology and Universals, $39(1-4), 19-28$.

Keating, P. A. (2006). Phonetic encoding of prosodic structure. In J. Harrington \& M. Tabain (Eds.), Speech production: Models, phonetic processes, and techniques (pp. 167-186). Psychology Press.

Keating, P. A., Cho, T., Fougeron, C., \& Hsu, C.-S. (2003). Domain-initial strengthening in four languages. In M. J. Solé (Ed.), Papers in laboratory phonology VI: Phonetic interpretations (pp. 145-163). Cambridge University Press.

Keuleers, E. (2013). vwr: Useful functions for visual word recognition research (R package version 0.3.0). Retrieved from https://CRAN.R-project.org/package $=$ vwr

Klatt, D. H. (1976). Linguistic uses of segmental duration in English: Acoustic and perceptual evidence. The Journal of the Acoustical Society of America, 59(5), 1208-1221.

Kösling, K., Kunter, G., Baayen, R. H., \& Plag, I. (2013). Prominence in triconstituent compounds: Pitch contours and linguistic theory. Language and Speech, 56, 529-554.

Krakow, R. A. (1999). Physiological organization of syllables: A review. Journal of Phonetics, 27(1), 23-54.

Krull, D. (1997). Prepausal lengthening in Estonian: Evidence from conversational speech. In I. Lehiste, J. Ross (Ed.), Estonian prosody: Papers from a symposium (pp. 136-148). Institute of Estonian Language.

Kuperman, V., Pluymaekers, M., Ernestus, M., \& Baayen, H. (2007). Morphological predictability and acoustic duration of interfixes in dutch compounds. The Journal of the Acoustical Society of America, 121(4), 2261-2271.

Lee, J., Kim, S., \& Cho, T. (2019). Effects of morphological structure on intergestural timing in different prosodic-structural contexts in Korean [Conference session]. 19th International Congress of Phonetic Sciences (ICPhS) 5-9 August 2019, Melbourne, VIC, Australia.

Lee-Kim, S.-I., Davidson, L., \& Hwang, S. (2013). Morphological effects on the darkness of English intervocalic /1/. Laboratory Phonology, 4(2), 475-511.

Lehiste, I. (1960). Segmental and syllabic quantity in Estonian. In T. A. Sebeok (Ed.), American studies in Uralic linguistics (Uralic and Altaic Series 1) (pp. 21-82). Indiana University Press.

Levelt, W. J. M., Roelofs, A., \& Meyer, A. S. (1999). A theory of lexical access in speech production. Behavioral and Brain Sciences, 22, 1-38.

Lippus, P., Asu, E. L., Teras, P., \& Tuisk, T. (2013). Quantity-related variation of duration, pitch and vowel quality in spontaneous estonian. Journal of Phonetics, 41(1), 17-28.

Lippus, P., Tusik, T., Ots, N., \& Teras, P. (2020). Phonetic corpus of Estonian spontaneous speech v.1.0.6. https://doi.org/10.15155/1-00-0000-0000-0000-0012BL

Lohmann, A. (2018). Cut (n) and cut (v) are not homophones: Lemma frequency affects the duration of nounverb conversion pairs. Journal of Linguistics, 54(4), 753-777.

Lõo, K., Järvikivi, J., \& Baayen, R. H. (2018). Whole-word frequency and inflectional paradigm size facilitate Estonian case-inflected noun processing. Cognition, 175, 20-25.

Lõo, K., Järvikivi, J., Tomaschek, F., Tucker, B. V., \& Baayen, R. H. (2018). Production of Estonian caseinflected nouns shows whole-word frequency and paradigmatic effects. Morphology, 28, 71-97.

Menzerath, P. (1928). Über einige phonetische Probleme [About some phonetic problems]. In A. W. Sijthoff (Ed.), Actes du premier Congres international de linguistes. Sijthoff Leiden.

Menzerath, P. (1954). Die Architektonik des deutschen Wortschatzes [The architecture of the German vocabulary]. Phonetische Studien, 3, 415-443.

Mihkla, M. (2006). Pausid kõnes [Pauses in speech]. Keel ja Kirjandus, 49(4), 286-295.

Moscoso del Prado Martín, F., Kostic, A., \& Baayen, R. H. (2004). Putting the bits together: An information theoretical perspective on morphological processing. Cognition, 94, 1-18.

Pierrehumbert, J. B. (2001). Exemplar dynamics: Word frequency, lenition, and contrast. In J. L. Bybee \& P. J. Hopper (Eds.), Frequency effects and the emergence of lexical structure (pp. 137-157). John Benjamins. 
Pitt, M. A., Dilley, L., Johnson, K., Kiesling, S., Raymond, W., Hume, E., \& Fosler-Lussier, E. (2007). Buckeye corpus of conversational speech (2nd release). Department of Psychology, Ohio State University.

Plag, I. (2014). Phonological and phonetic variability in complex words: An uncharted territory. Italian Journal of Linguistics, 26(2), 209-228.

Plag, I., Homann, J., \& Kunter, G. (2017). Homophony and morphology: The acoustics of word-final s in English. Journal of Linguistics, 53(1), 181-216.

Plag, I., Lohmann, A., Hedia, S. B., \& Zimmermann, J. (2020). An S is an 'S, or is it? plural and genitiveplural are not homophonous. In L. Körtvélyessy \& P. Štekauer (Eds.), Complex words: Advances in morphology (pp. 260-285). Cambridge University Press.

Porretta, V., Tucker, B. V., \& Järvikivi, J. (2016). The influence of gradient foreign accentedness and listener experience on word recognition. Journal of Phonetics, 58, 1-21.

Quirk, R., Greenbaum, S., Leech, G., \& Svartvik, J. (1985). A comprehensive grammar of the English language. Longman.

Ramscar, M. (2021). A discriminative account of the learning, representation and processing of inflection systems. Language, Cognition and Neuroscience. Advance online publication. https://doi.org/10.1080/ 23273798.2021.2014062

Ramscar, M., Yarlett, D., Dye, M., Denny, K., \& Thorpe, K. (2010). The effects of feature-label-order and their implications for symbolic learning. Cognitive Science, 34(6), 909-957.

Raymond, W. D., Dautricourt, R., \& Hume, E. (2006). Word-internal/t, d/deletion in spontaneous speech: Modeling the effects of extra-linguistic, lexical, and phonological factors. Language Variation and Change, 18(1), 55-97.

Roelofs, A. (1997). The WEAVER model of word-form encoding in speech production. Cognition, 64(3), 249-284.

Rose, D. (2017). Effects of morphological predictability on the acoustics of short morphemes $[\mathrm{PhD}$ Dissertation, University of Canterbury, Christchurch].

Scarborough, R. (2013). Neighborhood-conditioned patterns in phonetic detail: Relating coarticulation and hyperarticulation. Journal of Phonetics, 41(6), 491-508.

Schlechtweg, M., \& Corbett, G. G. (2021). The duration of word-final s in English: A comparison of regularplural and pluralia-tantum nouns. Morphology, 31, 383-407.

Schmitz, D., Plag, I., Baer-Henney, D., \& Stein, S. D. (2021). Durational differences of word-final /s/ emerge from the lexicon: Modelling morpho-phonetic effects in pseudowords with linear discriminative learning. Frontiers in Psychology, 12, Article 680889.

Schreuder, R., \& Baayen, R. H. (1995). Modeling morphological processing. In L. B. Feldman (Ed.), Morphological aspects of language processing (pp. 131-154). Lawrence Erlbaum.

Schuppler, B., van Dommelen, W. A., Koreman, J., \& Ernestus, M. (2012). How linguistic and probabilistic properties of a word affect the realization of its final/t/: Studies at the phonemic and sub-phonemic level. Journal of Phonetics, 40(4), 595-607.

Seyfarth, S. (2014). Word informativity influences acoustic duration: Effects of contextual predictability on lexical representation. Cognition, 133(1), 140-155.

Seyfarth, S., Garellek, M., Gillingham, G., Ackerman, F., \& Malouf, R. (2018). Acoustic differences in morphologically-distinct homophones. Language, Cognition and Neuroscience, 33(1), 32-49.

Simpson, A. P. (2009). Phonetic differences between male and female speech. Language and Linguistics Compass, 3(2), 621-640.

Smith, R., Baker, R., \& Hawkins, S. (2012). Phonetic detail that distinguishes prefixed from pseudo-prefixed words. Journal of Phonetics, 40(5), 689-705.

Song, J. Y., Demuth, K., Shattuck-Hufnagel, S., \& Ménard, L. (2013). The effects of coarticulation and morphological complexity on the production of english coda clusters: Acoustic and articulatory evidence from 2-year-olds and adults using ultrasound. Journal of Phonetics, 41(3-4), 281-295.

Strycharczuk, P. (2019). Phonetic detail and phonetic gradience in morphological processes. In R. Lieber (Ed.), Oxford research encyclopedia of linguistics.

Taft, M., \& Hambly, G. (1986). Exploring the cohort model of spoken word recognition. Cognition, 22, 259-282. 
Tang, K., \& Bennett, R. (2018). Contextual predictability influences word and morpheme duration in a morphologically complex language (Kaqchikel Mayan). The Journal of the Acoustical Society of America, 144(2), 997-1017.

Tily, H., \& Kuperman, V. (2012). Rational phonological lengthening in spoken Dutch. The Journal of the Acoustical Society of America, 132(6), 3935-3940.

Tomaschek, F., Hendrix, P., \& Baayen, R. H. (2018). Strategies for addressing collinearity in multivariate linguistic data. Journal of Phonetics, 71, 249-267.

Tomaschek, F., Plag, I., Ernestus, M., \& Baayen, R. H. (2019). Phonetic effects of morphology and context: Modeling the duration of word-final S in English with naïve discriminative learning. Journal of Linguistics, 57(1), 123-161.

Tomaschek, F., \& Ramscar, M. (2022). Understanding the phonetic characteristics of speech under uncertainty-Implications of the representation of linguistic knowledge in learning and processing. Frontiers in Psychology, 13, Article 754395.

Tomaschek, F., Tucker, B. V., Fasiolo, M., \& Baayen, R. H. (2018). Practice makes perfect: The consequences of lexical proficiency for articulation. Linguistics Vanguard, 4(s2), 1-13.

Tomaschek, F., Tucker, B. V., Ramscar, M., \& Baayen, R. H. (2021). Paradigmatic enhancement of stem vowels in regular English inflected verb forms. Morphology, 31, 171-199.

Torreira, F., \& Ernestus, M. (2012). Weakening of intervocalic/s/ in the Nijmegen Corpus of Casual Spanish. Phonetica, 69(3), 124-148.

Tremblay, A., \& Baayen, R. H. (2010). Holistic processing of regular four-word sequences: A behavioral and ERP study of the effects of structure, frequency, and probability on immediate free recall. In D. Wood (Ed.), Perspectives on formulaic language: Acquisition and communication (pp. 151-173). The Continuum International Publishing Group.

Tucker, B. V. (2019). Psycholinguistic approaches to morphology: Production. In Oxford research encyclopedia of linguistics. Oxford University Press.

Tucker, B. V., Sims, M., \& Baayen, R. H. (2019). Opposing forces on acoustic duration. https://psyarxiv. $\mathrm{com} / \mathrm{jc} 97 \mathrm{w}$

Vare, S. (2012). Eesti keele sõnapered: tänapäeva eesti keele sõnavara struktuurianalü̈s [The Database of Estonian Word Families: a Language Technology Resource]. Eesti Keele Sihtasutus.

Viitso, T.-R. (2003). Phonology, morphology and word formation. In M. Erelt (Ed.), Estonian language (pp. 9-92). Estonian Academy Publishers.

Viks, Ü. (1992). Väike vormisõnastik: sissejuhatus \& grammatika [ A Concise Morphological Dictionary of Estonian I: Introduction \& Grammar]. (Number v1). Eesti Teaduste Akadeemia, Keele ja Kirjanduse Instituut.

Whalen, D. H. (1991). Infrequent words are longer in duration than frequent words. The Journal of the Acoustical Society of America, 90(4), 2311-2311.

Wieling, M., Nerbonne, J., \& Baayen, R. H. (2011). Quantitative social dialectology: Explaining linguistic variation geographically and socially. PLOS ONE, 6(9), Article e23613.

Wood, S. N. (2017). Generalized additive models: An introduction with R. CRC Press.

Wright, C. E. (1979). Duration differences between rare and common words and their implications for the interpretation of word frequency effects. Memory \& Cognition, 7(6), 411-419.

Zimmermann, J. (2016). Morphological status and acoustic realization: Findings from New Zealand English. December 6-9, 2016. In C. Carignan \& M. D. Tyler (Eds.), Proceedings of the 16th Australasian International Conference on Speech Science and Technology (pp. 6-9). Parramatta Australia. 